\title{
Sildenafil Sebagai Pilihan Terapi Hipertensi Pulmonal Pascabedah Jantung Koreksi Penyakit Jantung Bawaan pada Anak
}

\author{
Yogi Prawira, Piprim B. Yanuarso \\ Departemen Ilmu Kesehatan Anak, RS Dr Cipto Mangunkusumo, Fakultas Kedokteran Universitas \\ Indonesia, Jakarta
}

\begin{abstract}
Definisi hipertensi pulmonal (HP) pada anak dan dewasa adalah sama, yaitu bila mean pulmonary arterial pressure $\geq 25 \mathrm{mmHg}$ saat istirahat atau $\geq 30 \mathrm{mmHg}$ saat aktivitas. Pada anak pascabedah koreksi penyakit jantung bawaan (PJB), HP berat merupakan komplikasi yang sangat dikhawatirkan, dengan angka kejadian sekitar 2\%. Sildenafil telah digunakan secara luas pada pasien HP dewasa, baik sebagai terapi tunggal maupun kombinasi. Makalah ini bertujuan untuk mengevaluasi pemberian sildenafil pada anak dengan HP pascabedah jantung koreksi. Kedua pasien dirujuk ke RS Dr Cipto Mangunkusumo, Jakarta (RSCM) dengan keluhan tampak biru, sesak terutama saat menetek, dan berat badan sulit naik. Saat itu kedua pasien didiagnosis memiliki kelainan jantung bawaan berupa transposisi arteri besar (TGA), defek septum ventrikel (VSD) dan HP. Operasi koreksi total (arterial switch dan penutupan VSD) dilakukan pada saat pasien pertama berusia 3 bulan 10 hari dan pasien kedua berusia 4 bulan 22 hari. Kedua pasien mendapat inhalasi nitric oxide (iNO), inhalasi iloprost, dikombinasikan dengan sildenafil oral, dengan dosis awal 0,5 $\mathrm{mg} / \mathrm{kg}$ berat badan $(\mathrm{BB})$ per kali tiap 6 jam dengan pemantauan tekanan arteri berkala. Pasien pertama dipulangkan pada hari ke-23 pascabedah dan mendapat sildenafil oral dengan penurunan dosis bertahap dalam kurun waktu 6 bulan. Pasien kedua dipulangkan pada hari ke-12 pascabedah dan masih mendapat terapi sildenafil oral dengan dosis yang sama sampai hari ini. Pada kedua pasien tidak dilaporkan kejadian efek samping. Sebagai kesimpulan sildenafil efektif dalam memperbaiki hemodinamika pembuluh darah pulmonal dan bekerja secara sinergik dengan iNO. Sildenafil oral merupakan terobosan terapi yang menarik dan cukup efektif karena mudah pemberiannya dan memiliki efek samping minimal. (Sari Pediatri 2010;11(6):456-462).
\end{abstract}

Kata kunci: hipertensi pulmonal, terapi, pascabedah, sildenafil, anak

\footnotetext{
Alamat korespondensi:

Dr. Piprim B. Yanuarso, Sp.A. Divisi Kardiologi Departemen Ilmu Kesehatan Anak FKUI-RSCM, Jl. Salemba 6, Jakarta 10430. Tel. 3147342, 315 5742, Fax. 3907743.
}

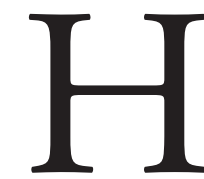

ipertensi pulmonal merupakan suatu keadaan meningkatnya tekanan vaskular paru akibat peningkatan tekanan arteri pulmonalis ataupun peningkatan tekanan arteri dan vena pulmonalis.1 Definisi HP pada anak 
Yogi Prawira dkk: Sildenafil sebagai pilihan terapi hipertensi pulmonal pascabedah jantung

dan orang dewasa adalah sama, yaitu bila mean pulmonary artery pressure (MPAP) $\geq 25 \mathrm{mmHg}$ saat istirahat atau $\geq 30 \mathrm{mmHg}$ saat aktivitas. 2

Etiologi HP pada anak cukup bervariasi. Menurut pengamatan yang dilakukan oleh Rosenzweig EB $\mathrm{dkk}^{3}$ di Amerika Serikat, penyakit jantung bawaan (PJB) merupakan penyebab yang paling sering ditemukan (56\%), diikuti oleh HP idiopatik (42\%). Pada anak pascabedah koreksi PJB, HP berat merupakan komplikasi yang sangat dikhawatirkan, dengan angka kejadian sekitar 2\%. ${ }^{4}$ Trauma bedah yang mengakibatkan kerusakan endotel selanjutnya dapat meningkatkan reaktivitas pembuluh darah paru, sehingga stress pascabedah dapat sangat meningkatkan tahanan vaskular paru. ${ }^{4}$

Sampai saat ini, literatur mengenai terapi HP pada anak, terutama yang berupa uji klinis, masih sangat terbatas. Tata laksana secara garis besar mengikuti algoritme tata laksana HP pada orang dewasa dengan beberapa penyesuaian. ${ }^{5}$ Terapi farmakologis yang saat ini digunakan untuk pengobatan HP meliputi golongan prostasiklin (epoprostenol), analog prostasiklin (beraprost, iloprost, treprostinil), antagonis reseptor endotelin (bosentan), nitric oxide (NO), inhibitor fosfodiesterase (sildenafil), serta kombinasi dari preparat-preparat tersebut. ${ }^{6,7}$ Kejadian HP pada anak selama ini memiliki prognosis yang buruk dengan angka kesintasan kurang dari satu tahun. ${ }^{5,6}$ Namun demikian, dengan adanya kemajuan dalam penegakan diagnosis, tata laksana, serta penerapan terapi spesifik dalam beberapa tahun terakhir, angka kesintasan mengalami perbaikan yang cukup nyata. ${ }^{5}$

\section{Kasus 1}

Seorang anak perempuan berusia tiga bulan datang dengan keluhan tampak biru sejak usia satu bulan. Sejak dua bulan sebelum dirawat, pasien sering tampak kebiruan di daerah lidah, bibir, dan ekstremitas. Berat badan sulit naik. Pasien hanya dapat minum ASI atau susu formula sedikit-sedikit, dalam tiga jam hanya mampu menghabiskan susu formula sebanyak $70 \mathrm{ml}$, dan sering terlihat sesak terutama saat minum.

Pasien lahir spontan, merupakan anak kembar, sebagai gemelli kedua mempunyai berat lahir $2100 \mathrm{~g}$, berat lahir gemelli pertama 2700 g. Pasien berasal dari keluarga sosioekonomi menengah-bawah. Riwayat kehamilan normal. Riwayat tumbuh kembang kesan terlambat. Imunisasi dasar lengkap. Asupan nutrisi kesan kurang.

Pada pemeriksaan fisis saat datang ke Poliklinik Pusat Jantung Terpadu (PJT) RSCM, keadaan pasien kompos mentis, tidak sesak, tampak sianosis pada lidah, bibir, dan ekstremitas, berat badan $3,5 \mathrm{~kg}$ $\left(<\mathrm{P}_{3}\right.$ kurva CDC NCHS 2000) dan panjang badan $56 \mathrm{~cm}\left(\mathrm{P}_{10}\right.$ kurva CDC NCHS 2000). Kesan klinis dan antropometris gizi kurang. Lingkar kepala 39 $\mathrm{cm}$ (normal). Tanda vital dalam batas normal. Pada pemeriksaan fisis jantung terdengar bunyi jantung I dan II normal, bising pansistolik grade III/6 dengan pungtum maksimum di sela iga III-IV garis parasternal kiri. Ekokardiografi menunjukkan transposisi arteri besar, defek septum ventrikel dan hipertensi pulmonal. Saat itu pasien didiagnosis transposisi arteri besar, defek septum ventrikel, hipertensi pulmonal, gizi kurang dan gagal tumbuh. Operasi koreksi total (arterial switch dan penutupan VSD) dilakukan saat pasien berusia 3 bulan 10 hari.

Pada perawatan hari pertama pascabedah, pasien mendapat terapi inhalasi NO 10 ppm yang dinaikkan bertahap sampai 20 ppm, dikombinasikan dengan inhalasi iloprost $2 \mu \mathrm{g}$ setiap dua jam. Pada perawatan pascabedah hari ke-3, pasien menunjukkan perbaikan klinis sehingga inhalasi NO dihentikan dan diberikan sildenafil $4 \times 1,5 \mathrm{mg}$ per oral dengan kombinasi inhalasi iloprost $2 \mu \mathrm{g}$ setiap enam jam. Selama perawatan, pasien mengalami beberapa episode perburukan klinis yang ditandai dengan perburukan perfusi berulang, perdarahan saluran cerna, dan ventilator-associated pneumonia. Pasien mendapat pengobatan suportif serta pemberian antibiotik yang sesuai, menunjukkan respons yang baik terhadap terapi, dan perbaikan keadaan umum sehingga dipulangkan pada hari ke23 pascabedah. Dosis sildenafil diturunkan bertahap dalam kurun waktu enam bulan. Ekokardiografi terakhir menunjukkan insufisiensi trikuspid ringan dengan pressure gradient $25 \mathrm{mmHg}$.

\section{Kasus 2}

Seorang anak laki-laki, berusia empat bulan, dirujuk ke Poliklinik PJT RSCM pada tanggal 17 Juli 2009 oleh dokter spesialis anak di Palembang dengan keterangan transposisi arteri besar dan defek septum ventrikel. Berdasarkan aloanamnesis dengan ibu pasien, sejak usia 40 hari pasien sering terlihat kebiruan di daerah lidah, 
bibir, dan ekstremitas yang tampak semakin jelas saat menangis atau menetek. Pasien mudah lelah, tampak sesak dan terengah-engah terutama bila menetek lama. Berat badan pasien sulit naik.

Pasien merupakan anak ketiga dari tiga bersaudara, dengan berat lahir $3700 \mathrm{~g}$, panjang lahir $50 \mathrm{~cm}$. Pasien berasal dari keluarga sosioekonomi menengah-bawah. Riwayat kehamilan dan persalinan normal. Riwayat tumbuh kembang kesan terlambat. Imunisasi dasar lengkap, namun asupan nutrisi kesan kurang.

Pada pemeriksaan fisis saat itu, pasien tampak kompos mentis, tidak sesak, tampak sianosis pada lidah, bibir dan ekstremitas, berat badan $4,8 \mathrm{~kg}\left(<\mathrm{P}_{3}\right.$ kurva CDC NCHS 2000) dan tinggi badan $58 \mathrm{~cm}$ ( $\mathrm{P}_{3}$ kurva CDC NCHS 2000). Kesan klinis dan antropometris gizi kurang. Lingkar kepala $41 \mathrm{~cm}$ (normal). Tanda vital dalam batas normal. Pada pemeriksaan fisis jantung terdengar bunyi jantung I normal, bunyi jantung II tunggal, tidak terdengar bising maupun irama derap. Pemeriksaan ekokardiografi menunjukkan transposisi arteri besar, defek septum ventrikel dan hipertensi pulmonal. Dilakukan tindakan kateterisasi menunjukkan dimensi PA dua kali lipat dari aorta dengan PA//Aorta : 91/35/61//100/58/75 mmHg. Saat itu pasien didiagnosis transposisi arteri besar, defek septum ventrikel, hipertensi pulmonal, gizi kurang dan gagal tumbuh. Operasi koreksi total (arterialswitch dan penutupan VSD) dilakukan pada saat pasien berusia 4 bulan 22 hari.

Pada perawatan hari pertama pascabedah, pasien menunjukkan gejala hipertensi pulmonal yang tidak berespons dengan inhalasi NO $20 \mathrm{ppm}$. Tekanan arteri pulmonalis dapat diturunkan dengan pemberian inhalasi iloprost dosis maksimal yang diberikan setiap dua jam, dikombinasikan dengan sildenafil 4x5 mg per oral. Hipertensi pulmonal mulai stabil pada perawatan pascabedah hari ke-3. Selama perawatan pasien mendapat pengobatan suportif dan pemberian antibiotik yang sesuai. Pasien menunjukkan perbaikan klinis, dipulangkan pada hari ke-12 pascabedah dengan terapi sildenafil oral.

\section{Masalah klinis}

Sampai saat ini penelitian mengenai terapi HP pada anak masih terbatas. Secara umum, tata laksana kasus pada anak mengikuti algoritme tata laksana orang dewasa. Berdasarkan hal tersebut, diajukan pertanyaan klinis sebagai berikut,

1. Pada anak dengan HP pascabedah koreksi PJB, apakah pemberian inhibitor fosfodiesterase (sildenafil) sebagai terapi tunggal memberikan hasil yang lebih baik dibandingkan dengan pengobatan lain seperti inhalasi $\mathrm{NO}$ dan inhalasi iloprost dalam memperbaiki hemodinamik pembuluh darah pulmonal?

2. Apakah pemberian inhibitor sildenafil sebagai terapi kombinasi memberikan hasil yang lebih baik dibandingkan dengan pengobatan lain tanpa sildenafil?

\section{Strategi penelusuran}

Untuk menjawab masalah klinis tersebut dilakukan penelusuran pustaka secara online menggunakan instrumen pencari Pubmed, Highwire, Cochrane Library, Google dan Yahoo. Kata kunci yang dipergunakan adalah "pulmonary hypertension" atau "pulmonary arterial hypertension", "therapy", "post operative" dan "sildenafil", dengan menggunakan batasan (limit): studi yang dilakukan pada anak, publikasi bahasa Inggris, publikasi 10 tahun terakhir, kata kunci terdapat pada judul atau abstrak, serta jenis publikasi berupa uji klinis, uji klinis terandomisasi, meta-analisis, dan review. Levels of evidence ditentukan atas dasar klasifikasi yang dikeluarkan oleh Oxford Centre for Evidence-based Medicine. ${ }^{8}$

\section{Hasil penelusuran}

Terdapat berbagai parameter keberhasilan yang dinilai dalam uji klinis pada HP, yaitu uji toleransi 6-minute walk distance (6-MWD), kelas fungsional WHO, penilaian hemodinamik pembuluh darah paru, dan kesintasan. Penilaian 6-MWD merupakan pemeriksaan standar untuk menilai kapasitas uji latih pada orang dewasa, namun sulit diterapkan pada anak. ${ }^{5}$

Meta-analisis yang dilakukan oleh Galie N dkk ${ }^{9}$ tahun 2009 mempelajari 23 uji klinis acak $(\mathrm{n}=3199)$ yang menilai keberhasilan terapi HP. Telaah ini menunjukkan peningkatan kesintasan pada pasien yang mendapat terapi spesifik HP. Pada 21 uji klinis, delapan di antaranya menilai efek pemberian prostanoid (epoprostenol intravena, treprostinil 
Yogi Prawira dkk: Sildenafil sebagai pilihan terapi hipertensi pulmonal pascabedah jantung

subkutan, inhalasi iloprost, dan beraprost oral), selanjutnya delapan uji klinis mengevaluasi terapi dengan antagonis reseptor endotelin (bosentan oral, sitaxsentan, dan ambrisentan), empat penelitian lainnya menilai efektivitas inhibitor fosfodiesterase (sildenafil), dan satu penelitian membahas penggunaan inhibitor sintase tromboksan terbogrel. Parameter yang digunakan untuk menilai keberhasilan terapi adalah uji toleransi 6-MWD, perbaikan kelas fungsional WHO/ NYHA, tekanan atrium kanan, MPAP, cardiac index, dan pulmonary vascular resistance (PVR). Seluruh hasil penelitian tersebut menunjukkan peningkatan yang bermakna $(\mathrm{p}<0,001)$ untuk semua parameter keberhasilan terapi (level of evidence: 1a). ${ }^{9}$ Hal serupa juga diungkapkan oleh Torres ${ }^{10}$ dalam sebuah metaanalisis yang melibatkan 15 uji klinis acak tersamar ganda yang mengamati penggunaan bosentan, sildenafil, sitaxsentan, dan ambrisentan (level of evidence: $1 \mathrm{a}) .^{10}$

Tahun 2003, Carroll WD dkk ${ }^{11}$ melaporkan serial kasus mengenai penggunaan sildenafil oral sebagai terapi HP pada tiga orang anak di Inggris. Dosis sildenafil yang diberikan pada pasien dimulai dari $0,5 \mathrm{mg} / \mathrm{kg}$ yang diberikan setiap enam jam, dan ditingkatkan secara bertahap. Meskipun dua dari tiga kasus tersebut berakhir dengan kematian, Carroll WD dkk ${ }^{11}$ menyatakan bahwa sildenafil merupakan pilihan terapi yang berguna bagi pasien anak dengan HP kronik yang berat (level of evidence: 4).

Schulze-Neick I dkk, ${ }^{12}$ di tahun yang sama menyampaikan hasil uji klinis yang menilai efektivitas sildenafil intravena pada anak pascabedah koreksi PJB. Berdasarkan studi tersebut diketahui bahwa penggunaan sildenafil intravena sebanding bahkan lebih baik dibandingkan dengan inhalasi NO dosis rutin dalam hal menurunkan peningkatan tahanan vaskular pembuluh darah pulmonal, baik selama berlangsungnya prosedur kateterisasi jantung rutin maupun pascabedah jantung terbuka (level of evidence: 2b). ${ }^{12}$

Penelitian terhadap obat yang sama juga dilakukan oleh Stocker $\mathrm{C} \mathrm{dkk}^{13}$ di Australia dalam suatu uji klinis acak. Dari penelitian tersebut diketahui bahwa penambahan sildenafil memperkuat efek vasodilator inhalasi NO. Pada kedua kelompok, pemberian sildenafil menurunkan tekanan darah sistemik dan tahanan vaskular sistemik $(\mathrm{p}<0,01)$. Namun demikian, sildenafil dapat menimbulkan hipotensi sistemik dan gangguan oksigenasi (level of evidence: $1 \mathrm{~b}) .^{13}$
Bentlin MR dkk ${ }^{14}$ pada tahun 2005 menyampaikan laporan kasus HP pada seorang bayi baru lahir dengan PJB yang menjalani prosedur Blalock Taussig Shunt. Pascabedah timbul HP yang terdiagnosis melalui kateterisasi jantung, disertai hipoksemia persisten, tanpa ada kelainan paru yang mendasarinya. Pasien kemudian mendapat terapi inhalasi NO 20 ppm, namun secara klinis tidak membaik hingga pasien mendapatkan pengobatan prostaglandin E1 (PGE1) intravena. Pada usia limapuluh hari, setelah upaya untuk menghentikan terapi PGE1 berulangkali gagal, atas persetujuan orangtua, pasien mulai mendapat sildenafil oral $0,5 \mathrm{mg} / \mathrm{kg}$ yang diberikan tiap enam jam. Dalam waktu 24 jam setelah pemberian sildenafil, tekanan arteri pulmonal turun dari $70 \mathrm{mmHg}$ menjadi $55 \mathrm{mmHg}$, pada akhir minggu pertama pemberian sildenafil, tekanan pulmonal menjadi $38 \mathrm{mmHg}$. Pada pasien tidak timbul hipotensi atau efek samping lainnya. Pasien dipulangkan limabelas hari kemudian dan tetap mendapat sildenafil oral selama 30 hari, dengan penurunan dosis secara bertahap (level of evidence: 4$).{ }^{14}$

Pada tahun yang sama, Humpl $\mathrm{T} \mathrm{dkk}^{15}$ juga mempublikasikan hasil uji klinis pendahuluan pemberian sildenafil oral pada anak. Di antara 14 pasien yang memenuhi kriteria, empat orang dengan diagnosis HP primer dan 10 orang dengan HP sekunder (tujuh orang pascabedah koreksi PJB, dan tiga orang dengan sindrom Eisenmenger). Dalam penelitian tersebut tampak adanya perbaikan pada uji 6-MWD dan hemodinamik pulmonal setelah pemberian sildenafil oral (level of evidence: $2 \mathrm{~b}$ ). ${ }^{15}$

Peiravian F dkk ${ }^{16}$ di Iran tahun 2007, mempublikasikan hasil uji klinis acak mengenai penggunaan sildenafil oral sebagai terapi HP pascabedah jantung koreksi. Pada studi tersebut penggunaan sildenafil oral dosis rendah tanpa pemberian vasodilator lain, terbukti efektif menurunkan tekanan pulmonal dan menurunkan risiko krisis HP tanpa risiko terjadi $\mathrm{HP}$ rebound (level of evidence: $1 \mathrm{~b}) .{ }^{16}$

\section{Pembahasan}

Dilaporkan dua kasus HP pada anak pascabedah koreksi PJB. Tata laksana HP pada anak secara garis besar mengikuti algoritme tata laksana pada orang dewasa dengan beberapa penyesuaian (Gambar 1).,

Tata laksana pasien HP pascabedah koreksi pada 
Yogi Prawira dkk: Sildenafil sebagai pilihan terapi hipertensi pulmonal pascabedah jantung

Tabel 1. Rangkuman penelitian penggunaan sildenafil pada anak

\begin{tabular}{|c|c|c|c|c|}
\hline Penulis & Pasien & Jenis penelitian & Keluaran & Hasil \\
\hline Carroll dkk ${ }^{11}(2003)$ & $\begin{array}{l}3 \text { anak (usia } 0-2 \\
\text { tahun) dengan } \\
1 \text { kasus pascabe- } \\
\text { dah }\end{array}$ & $\begin{array}{l}\text { Serial kasus (level of } \\
\text { evidence: } 4 \text { ) } \\
\text { Sildenafil oral } 0,5 \mathrm{mg} / \\
\mathrm{kg} \text {, tiap } 6 \text { jam }\end{array}$ & $\begin{array}{l}\text { Toleransi terhadap } \\
\text { aktivitas fisik }\end{array}$ & $\begin{array}{l}\text { Peningkatan toleransi } \\
\text { aktivitas fisik }\end{array}$ \\
\hline $\begin{array}{l}\text { Schulze-Neick dkk }{ }^{12} \\
(2003)\end{array}$ & $\begin{array}{l}12 \text { anak dengan } \\
\text { PJB \& MPAP } \\
\text { meningkat dan } \\
12 \text { anak pascabe- } \\
\text { dah dengan pe- } \\
\text { ningkatan PVR }\end{array}$ & $\begin{array}{l}\text { Prospektif, tidak } \\
\text { terandomisasi } \\
\text { (level of evidence: } 2 \mathrm{~b} \text { ) } \\
\text { Sildenafil iv } \\
0,25 \mathrm{mg} / \mathrm{kg} \text { dibanding- } \\
\text { kan dengan inhalasi } \\
\text { NO }\end{array}$ & $\begin{array}{l}\text { Tekanan vaskular } \\
\text { paru, tek. atrium } \\
\text { kanan-kiri, konsum- } \\
\text { si oksigen sistemik, } \\
\text { endtidal CO2 }\end{array}$ & $\begin{array}{l}\text { Sildenafil iv lebih efektif } \\
\text { dalam mengurangi tahanan } \\
\text { vena pulmonalis diban- } \\
\text { dingkan dengan NO }\end{array}$ \\
\hline Stocker $\mathrm{dkk}^{13}(2003)$ & $\begin{array}{l}16 \text { bayi } \\
\text { pasca VSD/ } \\
A S D \text { closure } \\
\text { yang beresiko } \\
\text { mengalami HP }\end{array}$ & $\begin{array}{l}\text { Prospektif, uji klinis } \\
\text { acak (level of evidence: } \\
\text { 1b) inhalasi NO } \\
\text { dilanjutkan dengan } \\
\text { sildenafil intravena } \\
0,35 \mathrm{mg} / \mathrm{kg}\end{array}$ & $\begin{array}{l}\text { Tekanan vaskular, } \\
\text { cardiac output, } \\
\text { \&AGD setelah } \\
\text { pemberian }\end{array}$ & $\begin{array}{l}\text { Sildenafil iv memperkuat } \\
\text { efek vasodilator inhalasi } \\
\text { NO }\end{array}$ \\
\hline Bentlin $\mathrm{dkk}^{14}(2005)$ & 1 neonatus & $\begin{array}{l}\text { Laporan kasus (level of } \\
\text { evidence: } 4 \text { ) } \\
\text { Sildenafil oral } 0,5 \mathrm{mg} / \\
\mathrm{kg} \text {, tiap } 6 \text { jam }\end{array}$ & $\begin{array}{l}\text { Tekanan vaskular } \\
\text { paru }\end{array}$ & $\begin{array}{l}\text { Sildenafil oral memperbaiki } \\
\text { hemodinamik pulmonal } \\
\text { pascabedah koreksi PJB }\end{array}$ \\
\hline Humpl dkk ${ }^{15}$ (2005) & $\begin{array}{l}14 \text { anak } \\
\text { (4 dengan } \mathrm{HP} \\
\text { primer, } 7 \mathrm{HP} \\
\text { pascabedah pada } \\
\text { PJB, } 3 \text { sindrom } \\
\text { eisenmenger) }\end{array}$ & $\begin{array}{l}\text { Uji klinis pendahuluan } \\
\text { (level of evidence: } 2 \mathrm{~b} \text { ) } \\
\text { Sildenafil 0,25-0,5 mg/ } \\
\mathrm{kg} \text {, tiap } 6 \text { jam }\end{array}$ & $\begin{array}{l}\text { 6-MWD, tekanan } \\
\text { vaskular paru, kelas } \\
\text { fungsional WHO }\end{array}$ & $\begin{array}{l}\text { Sildenafil oral meningkat- } \\
\text { kan hemodinamik pulmo- } \\
\text { nal dan kapasitas fisik }\end{array}$ \\
\hline Peiravian $\mathrm{dkk}^{16}(2007)$ & $\begin{array}{l}42 \text { anak } \\
\text { pascabedah } \\
\text { koreksi PJB }\end{array}$ & $\begin{array}{l}\text { Uji klinis terandomisasi } \\
\text { (level of evidence: } 1 \mathrm{~b} \text { ) } \\
\text { Sildenafil oral } 0,3 \mathrm{mg} / \\
\mathrm{kg}\end{array}$ & $\begin{array}{l}\text { Tekanan vaskular } \\
\text { paru, lama penggu- } \\
\text { naan ventilasi meka- } \\
\text { nik, lama perawatan } \\
\text { di ICU, lama pera- } \\
\text { watan di RS }\end{array}$ & $\begin{array}{l}\text { Penggunaan sildenafil dosis } \\
\text { rendah tanpa disertai vaso- } \\
\text { dilator pulmonal lainnya, } \\
\text { efektif menurunkan teka- } \\
\text { nan pulmonal dan menu- } \\
\text { runkan resiko krisis HP } \\
\text { pascabedah koreksi PJB }\end{array}$ \\
\hline
\end{tabular}

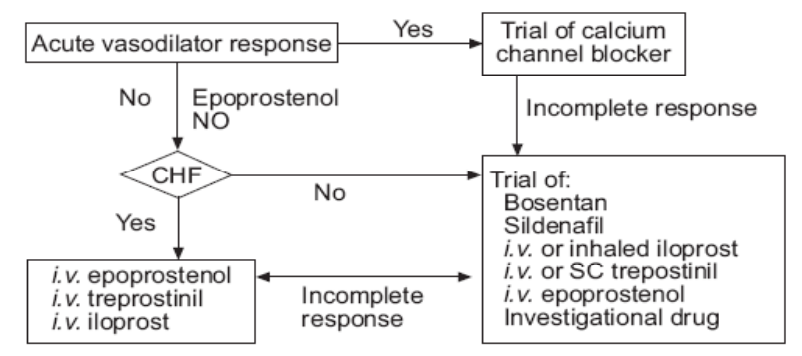

Gambar 1. Algoritma tata laksana hipertensi pulmonal pada anak ${ }^{5,7}$ (CHF:congenital heart failure, SC:subcutaneous) serial kasus yang disajikan adalah pemberian inhalasi NO, inhalasi iloprost, dan sildenafil oral. Pemberian inhalasi NO masih dianggap sebagai terapi standar HP pascabedah. ${ }^{16}$ Namun demikian, pada meta-analisis

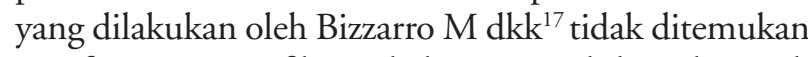
manfaat yang signifikan inhalasi NO pada bayi dan anak pascabedah koreksi PJB. Hal ini ditunjukkan dengan tidak adanya perubahan angka mortalitas, kejadian krisis HP, oksigenasi arterial, ataupun perubahan hemodinamik pulmonal pasca pemberian obat tersebut. ${ }^{17}$ Selain itu, jenis terapi tersebut memiliki beberapa kekurangan, yaitu masih ada kemungkinan terjadi krisis HP, HP 
rebound yang fatal akibat penghentian terapi, serta diperlukannya alat khusus dalam pemberiannya. ${ }^{16}$ Namachivayam $\mathrm{P} \mathrm{dkk^{18 }}$ pada penelitian uji klinis acak melaporkan bahwa dosis tunggal sildenafil dapat menghindari efek rebound dan mengurangi masa penggunaan ventilasi mekanik, sehingga pemberian sildenafil profilaksis dapat dipertimbangkan saat akan menyapih terapi inhalasi NO. ${ }^{18}$

Sildenafil merupakan inhibitor poten fosfodiesterase-5, dapat berakumulasi dan meningkatkan aktivitas cyclic guanosine monophosphate (cGMP), yang bekerja secara sinergik dengan NO. ${ }^{19}$ Sejak tahun 2005, Food and Drug Administration (FDA) menetapkan penggunaan sildenafil sebagai terapi $\mathrm{HP},{ }^{20}$ dan hingga saat ini merupakan obat yang paling sering digunakan pada pasien anak dengan HP sekunder. ${ }^{21}$ Penggunaan sildenafil cukup disukai karena kemasan oral sehingga mudah pemberiannya, efek samping relatif minimal, dan harga lebih terjangkau dibandingkan dengan terapi spesifik HP lainnya. ${ }^{22}$ Dosis sildenafil yang lazim digunakan untuk anak $0,5-1 \mathrm{mg} / \mathrm{kg}$, diberikan 3-4 kali sehari. Pemberian sildenafil dalam dosis besar dapat menimbulkan efek samping seperti ereksi, dan hipotensi sistemik. ${ }^{21}$

Pada serial kasus yang kami sajikan, respons pemberian sildenafil sesuai dengan hasil telaah sistematis Raja SG dkk, ${ }^{23}$ yaitu kondisi klinis pasien pascabedah koreksi PJB membaik yang ditandai dengan perbaikan hemodinamik pulmonal. Terapi dengan sildenafil oral pada pasien pertama dilanjutkan hingga enam bulan, kemudian dosis diturunkan bertahap sampai obat dihentikan.

Pemberian inhalasi iloprost pada kasus kami sesuai dengan bukti yang ada. ${ }^{24}$ Terapi kombinasi inhalasi iloprost dengan inhibitor fosfodiesterase ataupun antagonis reseptor endotelin dapat ditoleransi dengan baik. Namun demikian, harus diwaspadai pemakaian obat kombinasi tersebut dalam jangka panjang karena dapat memicu terjadinya bronkokonstriksi. ${ }^{24}$ Penggunaan bosentan oral sebagai terapi HP pada anak pernah dilaporkan oleh Rosenzweig EB $\mathrm{dkk}^{3}$, namun sayangnya saat ini obat tersebut belum tersedia di Indonesia.

\section{Kesimpulan}

Saat ini terdapat sejumlah bukti pilihan tata laksana HP pada anak. Sildenafil tampaknya efektif dalam memperbaiki hemodinamik pembuluh darah pulmonal dan bekerja sinergik dengan NO. Namun demikian, belum ada satu jenis obatpun yang terbukti lebih baik dibandingkan obat lainnya. Sildenafil oral merupakan terobosan terapi yang menarik dan cukup efektif karena mudah dalam pemberian, memiliki efek samping minimal dan harganya lebih murah dibandingkan dengan pilihan terapi lain. Uji klinis acak dengan jumlah sampel besar dari berbagai pusat penelitian masih diperlukan untuk menetapkan keamanan serta dosis optimal sildenafil pada anak.

\section{Daftar Pustaka}

1. Priyatno A. Hipertensi pulmonal pada penyakit jantung bawaan. Dalam: Putra ST, Roebiono PS, Rahayuningsih SE, Wulandari DA, penyunting. Towards competencebased practice in pediatric cardiology. Kongres Nasional I Perhimpunan Kardiologi Anak Indonesia dan Pertemuan Ilmiah Tahunan IV Kardiologi Anak; 2007 Sept 7-9; Bandung, Indonesia. Perhimpunan Kardiologi Anak Indonesia, 2007.h.78-89.

2. Hawkins A, Tulloh R. Treatment of pediatric pulmonary hypertension. Vascular health and risk .anagement 2009;5:509-24.

3. Rosenzweig EB, Ivy DD, Widlitz A, Doran A, Claussen LR, Yung D, dkk. Effects of long-term bosentan in children with pulmonary arterial hypertension. J Am Coll Cardiol 2005;46:697-704.

4. Lindberg L, Olsson AK, Jogi P, Jonmarker C. How common is severe pulmonary hypertension after pediatric cardiac surgery? J Thorac Cardiovasc Surg 2002;123:1155-63.

5. Beghetti M. Paediatric pulmonary hypertension: monitoring progress and identifying unmet needs. Eur Respir Rev 2009;18:18-23.

6. Widlitz A, Barst RJ. Pulmonary arterial hypertension in children. Eur Respir J 2003;21:155-76.

7. Rashid A, Ivy D. Severe paediatric pulmonary hypertension: new management strategies. Arch Dis Child 2005;90:92-8.

8. Oxford Centre of Evidence-based Medicine. Oxford Centre for evidence-based medicine levels of evidence (March 2009). Diunduh dari: http://www.cebm.net/index. asox?o=1025. Diakses tanggal 8 Oktober 2009.

9. Galie N, Manes A, Negro L, Palazzini M, Reggiani MLB, Branzi A. A meta-analysis of randomized controlled trials in pulmonary arterial hypertension. Eur Heart J 
2009;30:394-403.

10. Torres F. Systematic review of randomized, doubleblind clinical trials of oral agents conducted in patients with pulmonary arterial hypertension. J Clin Pract 2007;61:1756-65.

11. Carroll WD, Dhillon R. Sildenafil as a treatment for pulmonary hypertension. Arch Dis Child 2003;88:827-8.

12. Schulze-Neick I, Hartenstein P, Lia J, Stiller B, Nagdyman N, Hubler M, dkk. Circulation 2003;108(suppl II):16773.

13. Stocker C, Penny DJ, Brizard Cp, Cochrane AD, Soto $\mathrm{R}$, Shekerdemian LS. Intravenous sildenafil and inhaled nitric oxide: a randomised trial in infants after cardiac surgery[abstrak]. Intensive Care Med 2003;29:19962003.

14. Bentlin MR, Saito A, De Luca AKC, Bossolan G, Bonatto RC, Martins AS, dkk. Sildenafil for pulmonary hypertension treatment after cardiac surgery. J Pediatr (Rio J) 2005;81:175-8.

15. Humpl T, Reyes JT, Holtby H, Stephens D, Adatia I. Beneficial effect of oral sildenafil therapy on childhood pulmonary arterial hypertension: twelve-month clinical trial of single-drug, open-label, pilot study. Circulation 2005;111:3274-80.

16. Peiravian F, Amirghofran AA, Ajami GH, Sabri MR, Kolaee S. Oral sildenafil to control pulmonary hypertension after congenital heart surgery. Asian Cardiovasc Thorac Ann. 2007;15:113-7.

17. Bizzaro M, Gross I. Inhaled nitric oxide for the postoperative management of pulmonary hypertension in infants and children with congenital heart disease (review). The Cochrane Library: Wiley; 2009.h.1-26.

18. Namachivayam P, Theilen U, Butt WW, Cooper SM, Penny DJ, Shekerdemian LS. Sildenafil prevents rebound pulmonary hypertension after withdrawal of nitric oxide in children. Am J Respir Crit Care Med 2006;174:1042-7.

19. Khrisnan U, Lovig L. A review of sildenafil in the treatment of pediatric pulmonary arterial hypertension. Clinical Medicine: Theurapetics 2009;1:1329-33.

20. FDA approves pfizer's revatio as treatment for pulmonary arterial hypertension. Diunduh dari http://www.drugs. com/news/fda-approves-pfizer-s-revatio-pulmonary-arterialhypertension-1432.html. Diakses tanggal 8 Oktober 2009.

21. Haworth SG. The management of pulmonary hypertension in children. Arch Dis Child 2008;93:620-5.

22. McAuley DF. The current role of sildenafil citrate in the treatment of pulmonary arterial hypertension. Diunduh dari http://www.globalrph.com/sildenafil.htm.. Diakses tanggal 8 Oktober 2009.

23. Raja SG, MacArthur KJ, Pollock JC. Is sildenafil effective for treating pulmonary hypertension after pediatric heart surgey? Interact CardioVasc Thorac Surg 2006;5:52-4.

24. Ivy DD, Doran AK, Smith KJ, Mallory GB, Beghetti M, Barst RJ, dkk. Short- and long-term effects of inhaled iloprost therapy in children with pulmonary arterial hypertension. J Am Coll Cardiol 2008;51:161-9. 